\title{
Diphenyliodonium Salts with Pyranine Conk as an Environment-friendly Photo-acid Generator and Their Applications to Chemically Amplified Resists
}

\author{
Naohiro TARUMOTO, ${ }^{1, \dagger, \dagger \dagger}$ Nobukazu MiYAGawa, ${ }^{2}$ \\ Shigeru TAKAHARA, ${ }^{2}$ and Tsuguo YAMAOKA ${ }^{2}$ \\ ${ }^{1}$ Hodogaya Chemical Co., Ltd., 45 Miyukigaoka, Tsukuba 305-0841, Japan \\ ${ }^{2}$ Department of Information and Image Sciences, Faculty of Engineering, Chiba University, \\ 1-33, Yayoi-cho, Inage-ku, Chiba 263-8522, Japan
}

(Received November 22, 2004; Accepted April 12, 2005; Published August 15, 2005)

\begin{abstract}
A diphenyliodonium salt with an environment-friendly dye as anion was designed. This salt was shown to possess photosensitivity suitable for use as a chemically amplified resist at both 365 and $405 \mathrm{~nm}$. PAG of tris(diphenyliodonium) 9-hydroxy-pyrene-1,4,6-trisulfonate had a negative Ames test, showed good thermal stability, and had a decomposition temperature of $199.9^{\circ} \mathrm{C}$. The quantum yield of acid generation upon irradiation was 0.63. The mechanism of acid generation was intramoleculor electron transfer from the excited dye moiety to the iodonium structure. The photosensitivities of PAG in a polymer with a $t$-butoxycarbonyl protecting group were 31 and $58 \mathrm{~mJ} / \mathrm{cm}^{2}$ for 365 and $405 \mathrm{~nm}$ light, respectively. [DOI 10.1295/polymj.37.545]

KEY WORDS Photo-acid Generator / Diphenyliodonium Salts / Environment-friendly Dye / Pyranine Conk /
\end{abstract}

Chemically amplified resists based on acid catalyzed reactions are used widely in semiconductor technology and resists. ${ }^{1-4}$

In these reactions, photo-acid generators (PAGs) that generate acids upon irradiation have played an important role. ${ }^{5-8}$

In general, PAGs must have a high sensitivity, a high thermal stability, ability to generate acid and high solubility in solvents and matrixes. It is important that PAGs and acid precursors are non-mutagenic.

PAGs are classified based on ionic structure, such as onium salts of sulfonate derivatives, and on their non-ionic structure, such as sulfonate derivatives of $\mathrm{N}$-hydroxynaphthaleneimide.

Among PAGs, onium salts have several advantages such as a high sensitivity, good thermal stability, and easily modified structure for the purposes of altering their spectral absorption. This has led to various onium salts being applied as PAGs in photolithography. PAGs with photosensitivities at 193 and $248 \mathrm{~nm}$ have been studied, but there are few reports regarding the PAGs with photosensitivities at $365^{9-13}$ and $405 \mathrm{~nm}$. It is also difficult to find many reports describing safe and environmentally sensitive technologies regarding PAGs.

In this study, environment-friendly PAG photosensitive at both 365 and $405 \mathrm{~nm}$ was investigated. Tris(diphenyliodonium) 9-hydroxy-pyrene-1,4,6-trisulfonate (PC-DPI, 1) has an iodonium compound as a cat- ion and an environment-friendly dye (pyranine conk, 2) as an anion, which acts as spectral sensitizer for the iodonium ion and acid precursor. This dye (2) is referred to as a fluorescent whitening dye used in cosmetics and shampoos.

\section{EXPERIMENTAL}

\section{Reagents}

All solvents in this study were commercially available and used after being dehydrated with molecular sieves.

\section{Materials}

Pyranine conk, 2 (Hodogaya Chemical Co., Ltd.), and diphenyliodonium chloride (Tokyo Kasei Kogyo Co., Ltd. DPI-Cl) were used as received. Tetrabromophenol blue (TBPB) and $p$-toluenesulfonic acid were purchased from Wako Pure Chemicals. Tetrabutylammonium hydroxide (TMAH, $2.38 \mathrm{wt} \%$ solution) was purchased from Tama Chemical Company.

Preparation of tris(diphenyliodonium) 9-hydroxy-pyrene-1,4,6-trisulfonate $3 \mathrm{H}_{2} \mathrm{O}$ PC-DPI (1)

$0.5 \mathrm{~g}(0.95 \mathrm{mmol})$ of 2 and $0.97 \mathrm{~g}(3.04 \mathrm{mmol})$ of DPI-Cl were dissolved together in water. The pyranine conk solution was added dropwise to the DPI$\mathrm{Cl}$ solution. This solution was stirred at $40{ }^{\circ} \mathrm{C}$ for $2 \mathrm{~h}$ and then filtered. PC-DPI was recrystallized twice

\footnotetext{
${ }^{\dagger}$ Present Address: Touhoku Hodogaya Co., Ltd., 4-5 Yashima-cho, Kooriyama 963-8802, Japan

${ }^{\dagger}$ To whom correspondence should be addressed (E-mail: taru@ hodogaya.co.jp).
} 

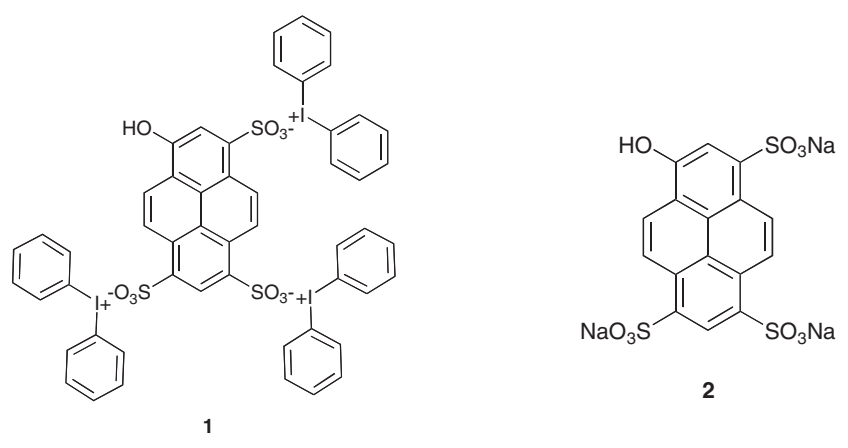

Figure 1. Structures of PAG (1) and Dye (2).

from water $(1.02 \mathrm{~g}, 79.4 \%)$. No attempt was made to maximize the product yield. MP $199.9^{\circ} \mathrm{C}$ (Decomposition temp.) Anal. Calcd for $\mathrm{C}_{52} \mathrm{H}_{43} \mathrm{I}_{3} \mathrm{O}_{13} \mathrm{~S}_{3}$ : C, 46.17; H, 3.20; I, 28.14; S, 7.11. Found: C, 45.57; H, 3.17; I, 28.03; S, 7.14. ${ }^{1} \mathrm{H}$ NMR (400 MHz, DMSO) $\delta$ $2.54(\mathrm{~s}, 6 \mathrm{H}), 7.52(\mathrm{t}, 12 \mathrm{H}), 7.64(\mathrm{t}, 6 \mathrm{H}), 8.15(\mathrm{~s}, 1 \mathrm{H})$, $8.24(\mathrm{~d}, 12 \mathrm{H}), 8.28(\mathrm{~d}, 1 \mathrm{H}), 8.86(\mathrm{~d}, 1 \mathrm{H}), 8.98(\mathrm{~m}, 3 \mathrm{H})$ and 10.63 (s, 1H); IR (KBr pellet) 3250, 1475, 1440, $1200,1060,975,740$ and $670 \mathrm{~cm}^{-1}$.

\section{Mutagenic Test}

The Ames test was used to examine the mutagenesic properties of PC-DPI and pyranine conk. The bacterium used in the test is a strain of Salmonella typhimurium that carries a defective gene making it unable to synthesize the amino acid histidine from the ingredients in its culture medium. However, some types of mutations can be reversed, referred to as a back mutation, with the gene regaining its function. These revertants grow on a medium lacking histidine.

A suspension of a histidine-dependent strain of Salmonella typhimurium was plated with a mixture of rat liver enzymes on agar lacking histidine. A filter paper disk was soaked with a DMSO solution with 10 or $50 \mu \mathrm{g}$ of chemical (PC-DPI or pyranine conk). The control filter paper disk was soaked with DMSO only. The mutagenic effect of the chemical caused two bacterial strains (TA-100, TA-98) to regain the ability to grow without histidine, forming colonies around the disk. If the number of the scattered colonies was more than that of the control, the chemical was considered mutagenic. When the number of the scattered colonies was equal to or less than that of the control, the chemical was not considered mutagenic.

\section{Measurements}

UV-vis spectra were recorded in $1.00 \times 1.00 \mathrm{~cm}$ quartz cells using a HITACHI U-3000 spectrophotometer.

Steady-state fluorescence spectra were recorded with samples in $1.00 \times 1.00 \mathrm{~cm}$ quartz cells in a HITACHI MPF-2A fluorescence spectrophotometer.
Thermal stability was analyzed using a SEIKO thermal analysis system TG/DTA-200.

Redox potentials were measured by cyclic voltammetry with a Hokuto-Denko Function Generator HB-104 and a potensiostat/galvanostat HA-301. Electrochemical measurements were carried out using a three-electrode cyclicvoltammetric cell. The working electrode was a platinum wire and the reference electrode was a calomel electrode. The electrolyte was $0.1 \mathrm{M}$ tetrabutylammonium perchlorate in DMF. The voltammograms were scanned at $50 \mathrm{mV} \mathrm{s}^{-1}$. All potentials were calculated $v$ s. SCE as $\mathrm{E}_{1 / 2}$ values, where $\mathrm{E}_{1 / 2}=0.5\left(\mathrm{E}_{\mathrm{pa}}+\mathrm{E}_{\mathrm{pc}}\right)$, where $\mathrm{E}_{\mathrm{pa}}$ and $\mathrm{E}_{\mathrm{pc}}$ are the anodic and cathodic peak potentials, respectively.

Acid generation yield was measured using TBPB as an acid indicator. ${ }^{12}$ An acetonitrile solution of PAG $\left(1.41 \times 10^{-5} \mathrm{~mol} \mathrm{dm}^{-3}\right)$ in a quartz cell was irradiated with $405 \mathrm{~nm}$ light through a filter from a super highpressure mercury lamp $\left(405 \mathrm{~nm}, 2.5 \mathrm{~mJ} / \mathrm{cm}^{2}\right)$. After irradiation, $3 \mathrm{~mL}$ of the solution were mixed with $1 \mathrm{~mL}$ of a TBPB acetonitrile solution $\left(5.59 \times 10^{-5}\right.$ mol $\mathrm{dm}^{-3}$ ), and the absorption spectrum of the mixture was measured. Changes in the absorption spectra of TBPB at $618 \mathrm{~nm}$ were compared.

\section{Lithographic Evaluation}

Photolithographic evaluation of the PAG photopolymer was based on the relationship between the exposure dose and the normalized film thickness after development. $1.0 \mu \mathrm{m}$ thickness film consisting of poly(4-t-buthoxycarbonyl-styrene) and photopolymer with $3 \mathrm{wt} \%$ PAG was prepared on a silicon wafer and pre-baked at $110^{\circ} \mathrm{C}$ for $2 \mathrm{~min}$. Exposure was carried out using a super high-pressure mercury lamp $\left(365 \mathrm{~nm}, 2.8 \mathrm{~mJ} / \mathrm{cm}^{2} ; 405 \mathrm{~nm}, 2.5 \mathrm{~mJ} / \mathrm{cm}^{2}\right)$. Exposed resists were post-exposure baked at $110^{\circ} \mathrm{C}$ for $5 \mathrm{~min}$ on a hot plate and developed in a $2 \mathrm{wt} \%$ TMAH solution for $12 \mathrm{~s}$.

\section{RESULTS AND DISCUSSION}

The results of the Ames test are shown in Table I. The number of revertant colonies for pyranine conk and PC-DPI was equal to that of the control. Pyranine conk and PC-DPI are thus not mutagens.

Table I. Ames test of pyranine conk and PC-DPI used two bacteria (TA-100 and TA-98)

\begin{tabular}{lcc}
\hline & \multicolumn{2}{c}{ The number of revertant colonies } \\
\cline { 2 - 3 } & TA-100 & TA-98 \\
\hline DMSO & 149 & 59 \\
Pyranine conk & 137 & 60 \\
PC-DPI & 123 & 61 \\
\hline
\end{tabular}




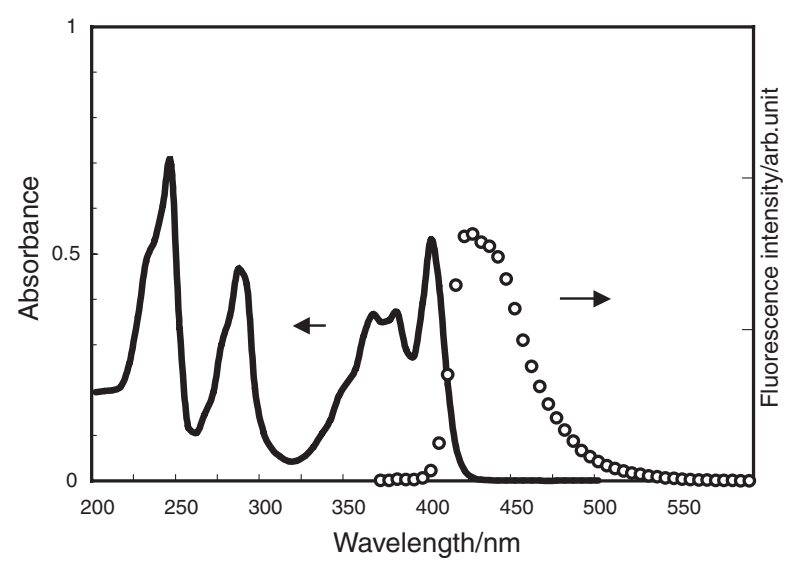

Figure 2. Absorption (-) and fluorescence $(\bigcirc)$ spectra of pyranine conk in $\mathrm{MeOH}$. Absorption spectrum of DPI-Cl (-) in $\mathrm{MeOH}$. The concentrations of pyranine conk and DPI-Cl were $2.18 \times 10^{-5}$ and $2.28 \times 10^{-5} \mathrm{~mol} \mathrm{dm}^{-3}$, respectively; the excitation wavelength was $365 \mathrm{~nm}$ in the fluorescence spectrum.

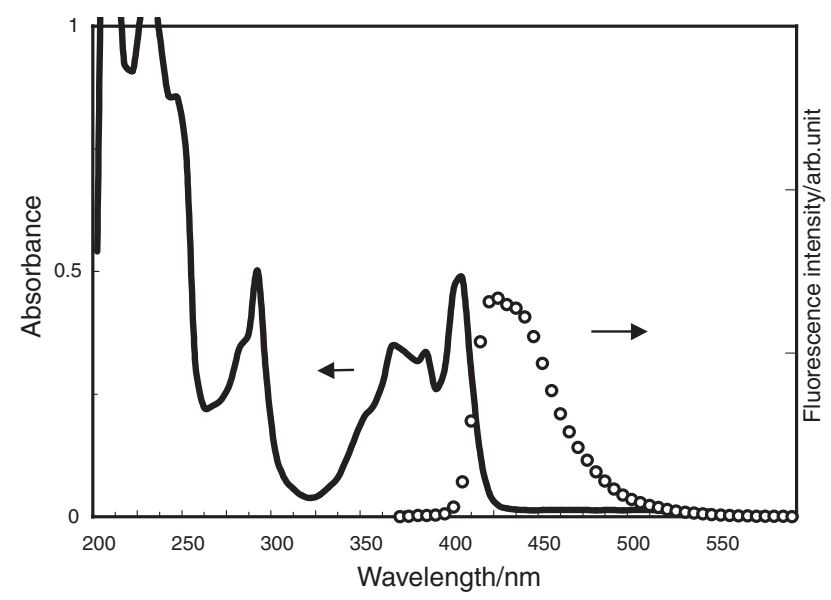

Figure 3. Absorption $(-)$ and fluorescence $(\bigcirc)$ spectra of PCDPI in $\mathrm{MeOH}$. The concentration of PC-DPI was $1.47 \times 10^{-5}$ mol dm${ }^{-3}$; the excitation wavelength was $365 \mathrm{~nm}$ in the fluorescence spectrum. Absorption coefficient of PC-DPI at $365 \mathrm{~nm}$ : $2.36 \times 10^{4} \mathrm{M}^{-1} \mathrm{~cm}^{-1}$.

Figure 2 shows the absorption spectra of pyranine conk and DPI-Cl and fluorescence spectrum of pyranine conk in oxygen-free $\mathrm{MeOH}$.

Pyranine conk has strong absorption peaks at 230 and $280 \mathrm{~nm}$, a broad absorption with a vibrational fine structure in the wavelength region of $310-420 \mathrm{~nm}$, and a broad and structureless fluorescence spectrum from 380 to $530 \mathrm{~nm}$. The absorption spectrum of pyranine conk clearly extends to longer wavelengths than that of DPI-Cl. From these spectra, the lowest excited singlet state energy $\left(\Delta \mathrm{E}_{00}\right)$ of pyranine conk was estimated as $69.6 \mathrm{kcal} / \mathrm{mol}$.

PC-DPI was synthesized by reacting pyranine conk and DPI-Cl in water. Figure 3 shows the absorption and fluorescence spectra of PC-DPI in oxygen-free $\mathrm{MeOH}$.
Electrochemical behavior was studied in DMF solution with tetrabutylammonium perchlorate as the supporting electrolyte. The oxidation potential $\left(\mathrm{E}_{1 / 2 \mathrm{ox}}\right)$ of pyranine conk was $0.79 \mathrm{~V} v s$. SCE and the reduction potential $\left(\mathrm{E}_{1 / 2}\right.$ red) of DPI-Cl was $-0.81 \mathrm{~V} v s$. SCE. The standard free energy changes $\left(\Delta G^{0}\right)$ accompanying the electron transfer from the lowest excited single state of pyranine conk to that of DPI thus can be calculated according to the Rehm-Weller equation,

$$
\Delta \mathrm{G}^{0}=23.06\left\{\mathrm{E}\left(\mathrm{D} / \mathrm{D}^{+\bullet}\right)-\mathrm{E}\left(\mathrm{A}^{-\bullet} / \mathrm{A}\right)\right\}-\Delta \mathrm{E}_{00}-\mathrm{C}
$$

where $E\left(D / D^{+\bullet}\right)$ is the oxidation potential of the donor, $\mathrm{E}\left(\mathrm{A}^{-\bullet} / \mathrm{A}\right)$ is the reduction potential of the acceptor, $\Delta \mathrm{E}_{00}$ is the electronic energy corresponding to the excited singlet state of the donor, and $\mathrm{C}$ is the Coulombic interaction energy, in this case $1-2 \mathrm{kcal} /$ mol in a polar solvent.

In the case of the pyranine conk anion and DPI cation in the PC-DPI molecule, $\Delta \mathrm{G}^{0}$ was calculated as $-32.7 \mathrm{kcal} / \mathrm{mol}$ without taking coulombic interactions into consideration. This estimation indicates that the intramolecular electron transfer from anion to cation could take place quantitatively.

Table II shows the decomposition temperatures of DPI-Cl, Pyranine conk, and PC-DPI. The decomposition temperatures of fluoreny-lideneiminononafluorobutane sulfonate, fluorenylideneiminotrifluoro methane sulfonate and diphenyliodonium 9,10-dimethoxyanthracene-2-sulfonate, other representative PAGs, are 146,135 , and $200{ }^{\circ} \mathrm{C}$, respectively. ${ }^{12}$ The thermal stability of the PAG developed in this study was equal to or higher than that of all of these other PAGs.

The thermal stability of PC-DPI may thus be considered adequate.

Acid generation yield was measured using TBPB as an acid indicator. The absorption band of TBPB at around $618 \mathrm{~nm}$ was changed by the presence of an acid. TBPB absorption changes were calibrated using $p$-toluenesulfonic acid as a standard material. Quantum yield was determined from the absorption changes at $618 \mathrm{~nm}$ due to acid generation. Quantum yield based on acid generation from PC-DPI was 0.63.

Quantum yields of diphenyliodonium 9,10-dimethoxyanthracene-2-sulfonate, $\mathrm{N}$-trifluoromethylsulfonyloxy-1,8-naphthalimide and fluorenylideneiminotrifluoromethanesulfonate are $0.18,0.17$, and 0.32 , respectively. ${ }^{10-12}$

Table II. Decomposition Temperatures of DPI-Cl, pyranine conk and PC-DPI

\begin{tabular}{lc}
\hline Compound & $T_{\mathrm{d}}\left({ }^{\circ} \mathrm{C}\right)$ \\
\hline DPI-Cl & 200 \\
Pyranine conk & $>400$ \\
PC-DPI & 199.9 \\
\hline
\end{tabular}




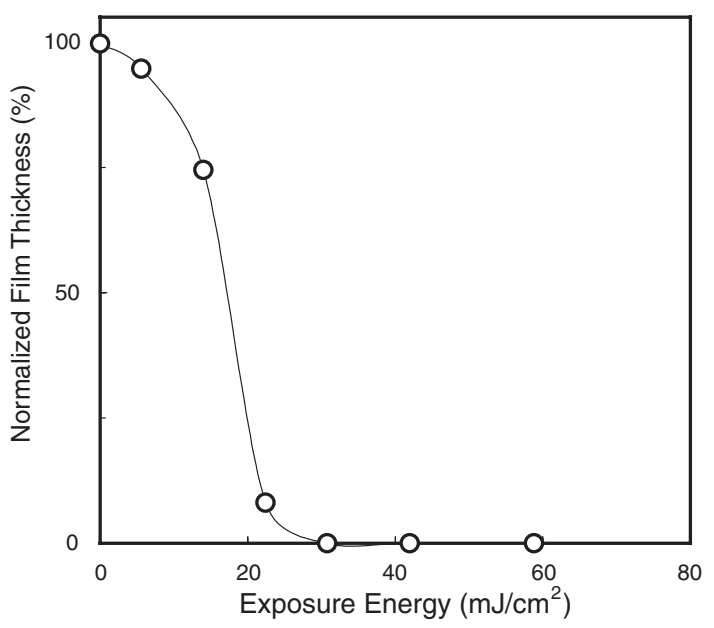

Figure 4. Characteristic curves of the photopolymer involved PC-DPI 3 wt \% (365 nm wavelength light).

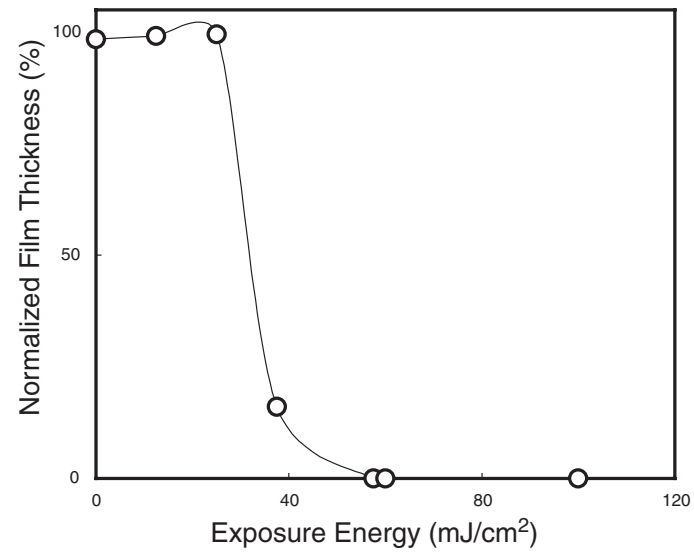

Figure 5. Characteristic curves of the photopolymer involved PC-DPI 3 wt \% (405 nm wavelength light).

Quantum yield of the PAG in this study was thus much higher than that of these PAGs, indicating higher acid generation yield for PC-DPI, and, thus, a higher reactivity.

Figures 4 and 5 show the relationship between the light exposure intensity and normalized film thickness after development at 365 and $405 \mathrm{~nm}$, respectively. The sensitivity of the new PAG was $31 \mathrm{~mJ} / \mathrm{cm}^{2}$ (Figure 4) and $58 \mathrm{~mJ} / \mathrm{cm}^{2}$ (Figure 5) for the two wavelengths. These results indicate that the photopolymer has sufficient sensitivity in the non-optimized step.

This is a positive working resist which shows solubility change due to deprotection by the acid from PAG and subsequent bake.

SEM micrograph of a pattern created from the photopolymer with $3 \mathrm{wt} \%$ PC-DPI is shown in Figure 6.

\section{CONCLUSIONS}

A new environmentally-friendly PAG with a non-

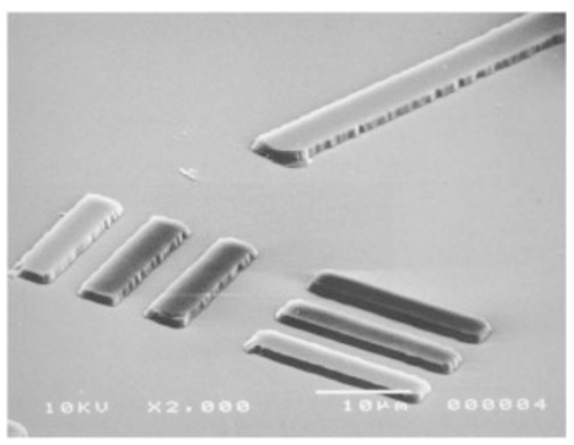

Figure 6. SEM photograph of the pattern from poly(4-tbuthoxycarbony-PHS) with PC-DPI 3 wt $\%$.

mutagenic dye was designed. This new PAG possesses the necessary qualities for use as a chemically amplified resist.

The Ames test indicated the PC-DPI to be nonmutagenic. Mechanism of acid generation is considered intramoleculor electron transfer from the excited dye part of the molecule to the iodonium structure. The thermal stability of PC-DPI was adequate for use as a chemically amplified resist. Quantum yield of acid generation was 0.63 . The photo-acid generating efficiency in a polymer with a $t$-buthoxycarbonyl protecting group was $31 \mathrm{~mJ} / \mathrm{cm}^{2}(365 \mathrm{~nm})$ and 58 $\mathrm{mJ} / \mathrm{cm}^{2}(405 \mathrm{~nm})$.

PC-DPI has sufficient potential at both 365 and $405 \mathrm{~nm}$ for use as a chemically amplified resist.

\section{REFERENCES}

1. J. V. Crivello and K. Dietliker, "Photoinitiators for Free Radical, Cationic and Anionic Photopolymerization," 2nd ed., G. Bradley Ed., Wiley and Sons, New York, N.Y., 1988, p 375.

2. J. V. Crivello and J. H. W. Lam, Macromolecules, 10, 1307 (1977).

3. J. V. Crivello and J. H. W. Lam, J. Polym. Sci., Polym. Chem. Ed., 17, 977 (1979).

4. C. Prou, A. Soldat, J. Cavezzan, F. Castellanos, and J. P. Fouassier, J. Coat. Technol., 67, 71 (1995).

5. T. X. Neenan, F. M. Houlihan, E. Reichmanis, J. M. Kometani, B. J. Bachman, and L. F. Thompson, Macromolecules, 23, 145 (1990).

6. T. Naito, K. Asakawa, N. Shida, T. Ushirogouchi, and M. Nakase, Jpn. J. Appl. Phys., Part 1, 33, 7028 (1994).

7. M. Nakase, T. Naito, K. Asakawa, A. Hongu, N. Shida, and T. Ushirogouchi, Proc. SPIE., 2438, 445 (1995).

8. M. Shirai and M. Tsunooka, Prog. Polym. Sci., 21, 1 (1996).

9. K. Naitoh, T. Yamaoka, and A. Umehara, Chem. Lett., 1869 (1991).

10. K. Naitoh, A. Umehara, and T. Yamaoka, Polym. Adv. Technol., 12, 414 (2000).

11. F. Ortica, J. C. Scaiano, G. Pohlers, J. F. Cameron, and A. Zampini, Chem. Mater., 12, 414 (2000). 
12. H. Okamura, K. Sakai, M. Tsunooka, and M. Shirai, J. Photopolym. Sci. Technol., 16, 701 (2003).

13. M. Shah, N. S. Allen, N. G. Salleh, T. Corrales, M. Edge,
F. Catalina, P. Bosch, and A. Green, J. Photochem. Photobiol. Part A, Chemistry, 111, 229 (1997). 